\title{
A Real-Time Smart Dumpsters Monitoring and Garbage Collection System Using Iot
}

\author{
S.Sivajothi Kavitha,K.Hemalatha V.Jamuna
}

\begin{abstract}
In most of the cities the overflowed garbage dumpsters are creating an obnoxious smell and making an unhygienic environment. The Collection of garbage is a very much needed municipal service that requires huge expenditures and execution of this operation is high-priced. The high pricing is due to the various factors such as man power, navigation of vehicles, fuel, maintenances and environmental costs. The above factor necessitates the design, implementation and execution of the new Smart Intelligent Garbage Alert System (SIGAS) for the smart cities. This paper focuses on the implementation of an IoT based embedded system which integrates various Sensors \& controllers with RF transmitter and receiver for dumpster and vehicle monitoring system with their performance measured in real time environment.
\end{abstract}

Keywords - Dumpsters, IoT, Smart Intelligent Garbage Alert System (SIGAS).

\section{INTRODUCTION}

Industrialization becomes very significant for developing countries like India having large number of populations. Rapid increase in urbanization and per capita income lead to high rate of municipal solid waste generation. Trash and garbage is a common sight in urban and rural areas of India. It is a major source of pollution. Indian cities alone generate more than 100 million tons of solid waste a year. Street corners are piled with trash. Public places and sidewalks are despoiled with filth and litter, rivers and canals act as garbage dumps. Municipalities in Indian cities and towns have waste collection employees. However, these are unionized government workers and their work performance is neither measured nor monitored. The main purpose of the SIGAS is to control overflowing of garbage and to make reduction of human resources. Thereby making the manual process of monitoring and verification of garbage dumpsters to be automated. Sharaaf N. A. et.al (2017) proposed "Easy Clean - A Smart Solution for Garbage Finding and collecting"

Revised Manuscript Received on July 22, 2019

S.Sivajothi Kavitha, Department of Electronics and Instrumentation Engg,, Jerusalem College of Engineering/ Chennai,Tamilnadu,India.

K.Hemalatha, Department of Electronics and Instrumentation Engg,, Jerusalem College of Engineering/ Chennai,Tamilnadu,India.

Dr.V.Jamuna, Department of Electronics and Instrumentation Engg,, Jerusalem College of Engineering/ Chennai,Tamilnadu,India. gives an idea about ultrasonic sensor which is interfaced with arduino mega. When the garbage level reaches a threshold limit, the level along with the unique ID provided is sent to the authorities from their place through Internet and an immediate action will be made to clean the dustbins.Mohd Talhaet.al(2017) "A Cloud integrated wireless garbage management system for Smart Cities" provides information about gas sensor, humidity sensor and garbage fill volume in waste bins. The data is monitored, analyzed and stored and notification is sent to the service providers for suitable action for fire prevention and waste bin overflow.Chaitanya Kumaret.al (2017)"Smart dustbin for economic growth" gives an idea about IR sensor which will observe a person nearby the dustbin. If motion is detected the lid of dustbin is opened which is activated by the servo motor.

Schafer G et.al (2017) "Garbage monitoring system using IoT".A different ID was provided to each bin so that it could be easier to detect which bin is full and ready to be emptied. The project is divided into two sections one being the transmitter section and other the receiver section. The data is passed onto the system with the help of the RF Transmitter, and then RF Receiver receives the data and sends it to the client associated so that the bin can be emptied quickly.Jamuna et.al proposed a gully pot monitoring system in which RFID tag was used to measure the level Bharadwaj B et.al "Automation of smart waste management using IoT to support Swachh Bharat Abhiyan- A practical approach"(2017) gives information about IoT module which is used to control and monitor the waste and the information will be sent to the authorities.

In the present condition garbage is not handled properly and consumes more resources because workers have to drive their large vehicles to every garbage collection point to check if dumpster is full or not. In order to overcome these issues this system has been proposed which aids for effective handling of the garbage. The proposed project deals with the handling of garbage linking the Internet of Things to garbage collection which will result in saving the fuel, work hours and money. The system consists of three sections: dumpster unit, vehicle unit and control unit. In the first section the level of the garbage in the dumpster which is placed in the streets is monitored. In case the level exceeds the threshold limit alert is sent to the authorities using IoT module. Presence of poisonous gases and humidity content inside the dumpster is monitored and in case the level exceeds an alert will be send to authorities. The authorities can take further action to empty the dumpster. The garbage collecting vehicles details are uploaded to server using RF Transmitter and Receiver. The vehicle unit is attached

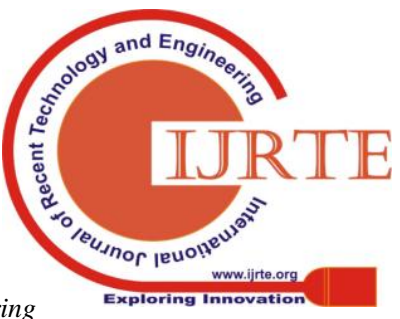


with the RF Transmitter; the RF Receiver is attached to the dumpster unit. The transmitted signal from vehicle is received in dumpster through receiver. Vehicle information with date and time is sent to the server. To avoid spilling of garbage on the road side a buzzer will be attached with the vehicle unit in order to alert the driver if the door of vehicle not closed. Solar panel is used to harness energy which ac as a source of energy.

\section{SMART INTELLIGENT GARBAGE ALERT SYSTEM}

This paper proposes a smart intellige garbage alert system for the collection of garbage and th details of garbage collecting vehicle. This system gives a alert signal to the municipal web server for regular cleanin of dumpster with proper verification based on level garbage filling. The proposed system consists of dumpst unit and vehicle unit which is given below

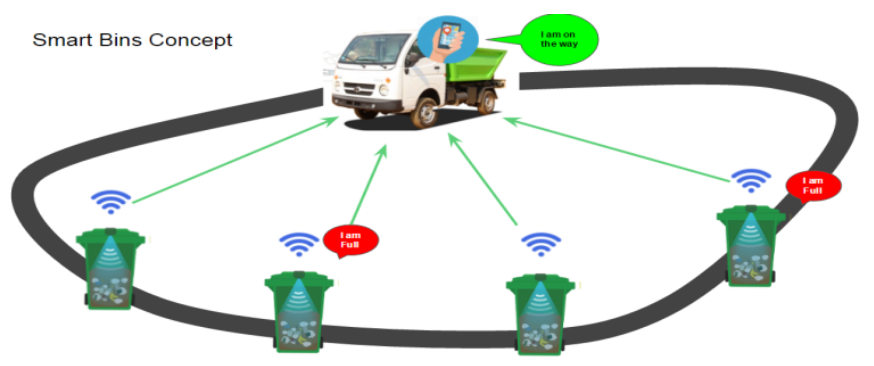

Fig 1: SIGAS unit

\section{Dumpster unit}

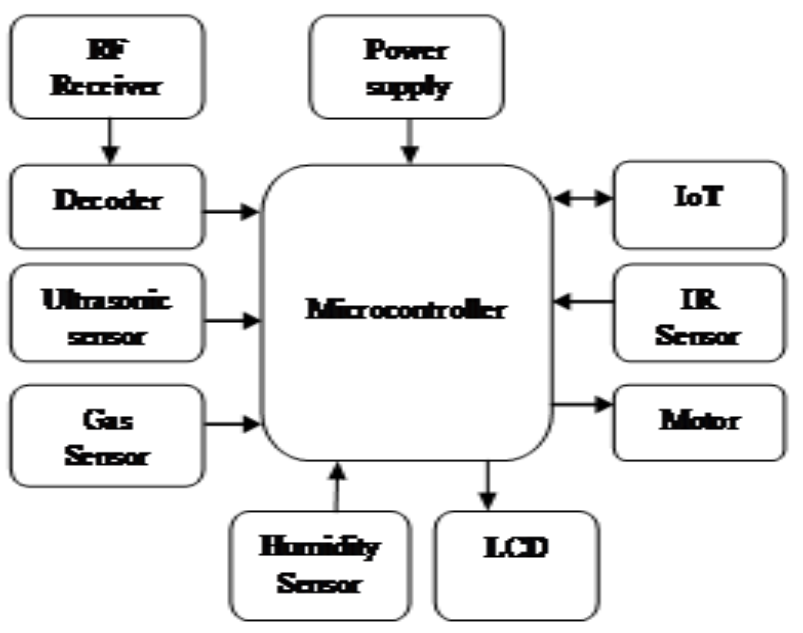

Fig 2: Bock diagram of dumpster unit

The dumpster unit consists of a Level sensor which provides authorities the capability of knowing the fill-level

of each dumpster in real time. This system also sends information about the presence of harmful gases and humidity content in the dumpster using the gas and humidity sensor .

\section{Vehicle unit}

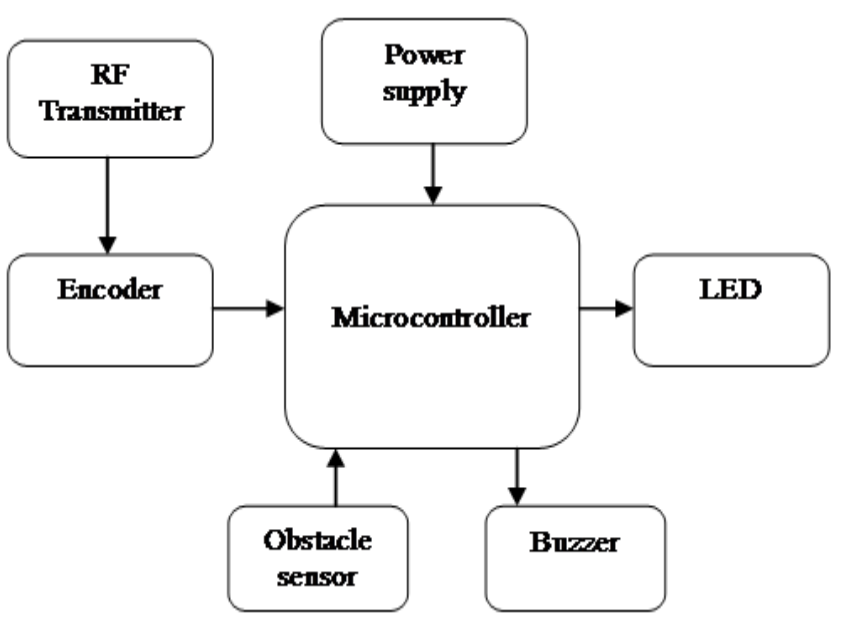

Fig 3: Bock diagram of vehicle unit

Vehicle unit transmits the garbage collecting vehicle information through RF module to the dumpster. In case the door of the vehicle is not closed properly buzzer or LED indication is given to the driver.

\section{III.HARDWARE IMPLEMENTATION}

\section{A. SENSOR SECTION}

\section{(i) ULTRASONIC SENSOR:}

The Ultrasonic Sensor is used to measure the distance with high accuracy and stable readings. It can measure distance from $2 \mathrm{~cm}$ to $400 \mathrm{~cm}$ or from 1 inch to 13 feet. It emits an ultrasound wave at the frequency of $40 \mathrm{KHz}$ in the air and if the object will come in its way then it will bounce back to the sensor. By using that time which it takes to strike the object and comes back, we can calculate the distance. Distance can be measured by equation 1 .

Distance $=$ Time $*$ sound speed $/ 2$.

Where Time $=$ the time between an ultrasonic wave is received and transmitted. It has four pins. Two are VCC and GND which will be connected to the 5V. Trig and Echo pins which will be connected to any digital pins of the Arduino. The trig pin will send the signal and the Echo pin will be used to receive the signal.

\section{(ii) GAS SENSOR}

MQ2 gas sensor is a Metal Oxide Semiconductor (MOS) type Gas Sensor as the detection is based upon change of resistance of the sensing material when the gas comes in contact with the material. It can detect LPG, smoke, alcohol, propane, hydrogen, methane and carbon monoxide concentrations from 200 to 10000 ppm. MQ2 Gas sensor works on $5 \mathrm{~V}$ DC and draws around $800 \mathrm{~mW}$.It consists of a small heater inside with an electrochemical sensor which changes its resistance for

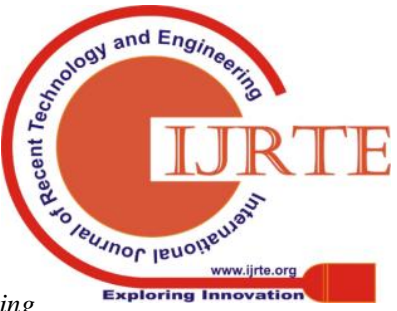


different concentration of gas. The analog output voltage provided by the sensor changes in proportion to the concentration of gas. The smoke sensor has a built-in potentiometer that allows us to adjust the sensor sensitivity.

\section{(iii) HUMIDITY SENSOR}

A humidity sensor senses, measures and regularly reports the relative humidity in the air. It measures both moisture and air temperature. Humidity sensors use capacitive measurement to determine the amount of moisture in the air. The humidity sensor is a small capacitor consisting of a hygroscopic dielectric material placed between a pair of electrodes. This type of measurement relies on two electrical conductors with a non-conductive polymer film lying between them to create an electrical field between them. Moisture from the air collects on the film and causes changes in the voltage levels between the two plates. This change is then converted into a digital measurement of the airs relative humidity after taking the air temperature into account.

\section{(iv) IR SENSOR}

An Infrared sensor is used to sense certain characteristics of its surroundings by either emitting or detecting the IR radiation. It usually consists of IR transmitter and receiver. A remote control patterns a flash of invisible light which is turned into an instruction and is received by the receiver module.

\section{(v) RF Transmitter and Receiver}

RF has transmitter and the receiver. The transmitter module takes serial input and transmits the signal through RF.The Receiver module is placed away from the source of transmission and the module receives the Transmitted signal. The system allows one-way communication between two nodes, namely transmission and reception. The parallel input is converted into serial set of signals by the encoder. These signals are serially transferred through RF to the reception point. After the RF receiver the decoder is used to decode the serial format and receive the original signal as output.

\section{B. MECHANICAL SECTION}

i) LCD

LCD (Liquid Crystal Display) screen is an electronic display module used for indication of commands. User can have visual information about the status of the bin.

\section{C.CONTROLLER SECTION}

In this system the Arduino Mega 2560 microcontroller is used. It has 54 digital input/output pins (of which 14 can be used as PWM outputs), 16 analog inputs, 4 UARTs (hardware serial ports), a $16 \mathrm{MHz}$ crystal oscillator, a USB connection, a power jack, an ICSP header, and a reset button. It contains everything needed to support the microcontroller; simply it is connected to a computer with a USB cable or powers it with a AC-to-DC adapter or battery to get started. It can be programmed with the Arduino software. The Atmega2560 on the Arduino Mega comes pre-burned with a boot loader that allows you to upload new code to it without the use of an external hardware programmer. It communicates using the original STK500 protocol.

\section{IV.HARDWARE INTEGRATION AND IMPLEMENTATION}

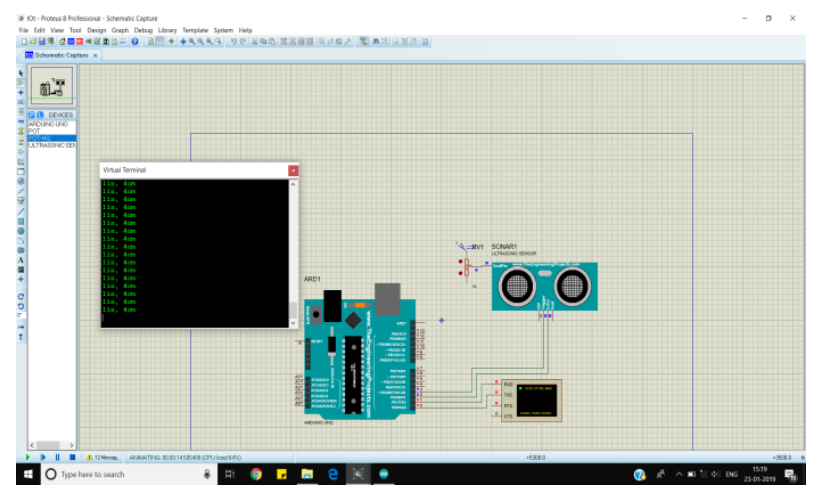

Fig:4 Simulation output

Proteus is a simulation and design software tool. Here proteus is used for the simulation of hardware.

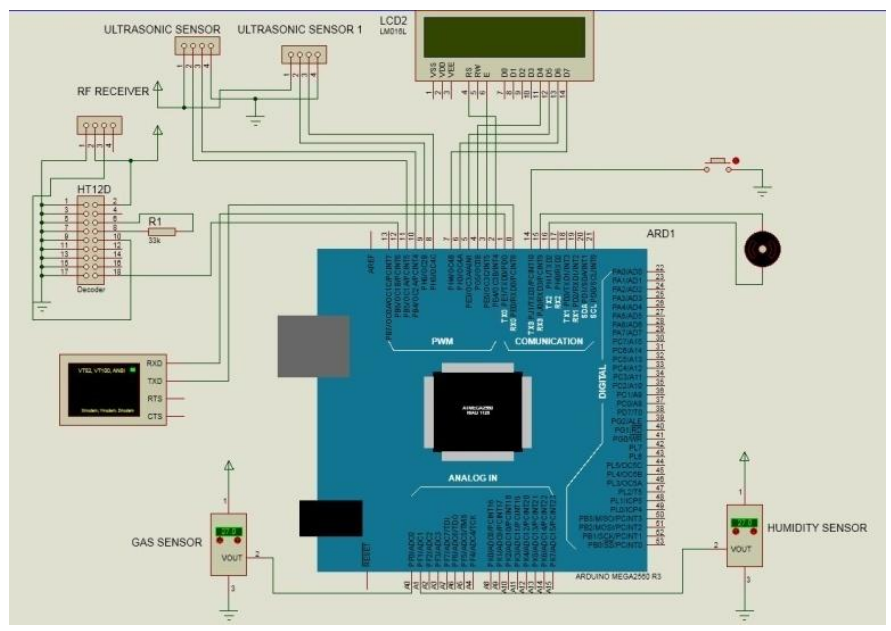




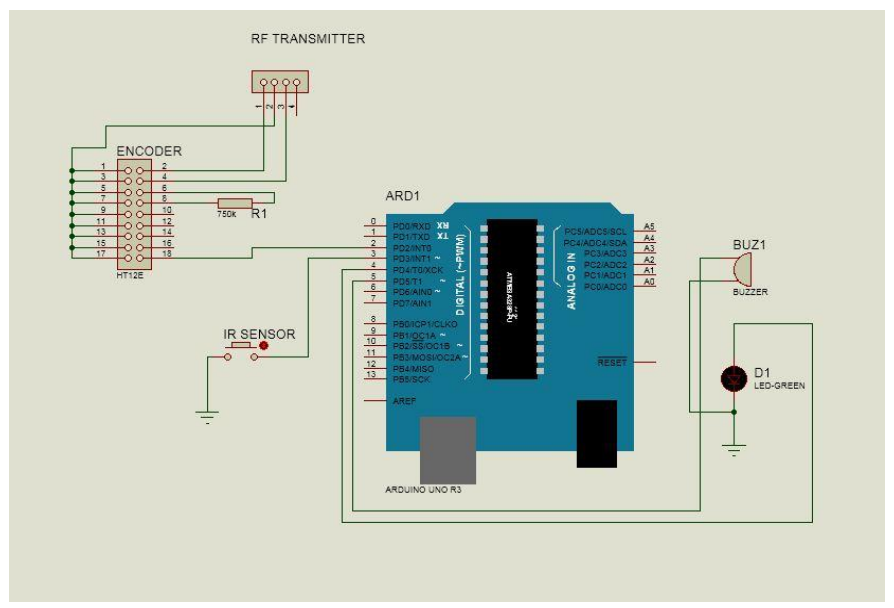

The Complete hardware setup of the Bin unit and Vehicle unit is shown below

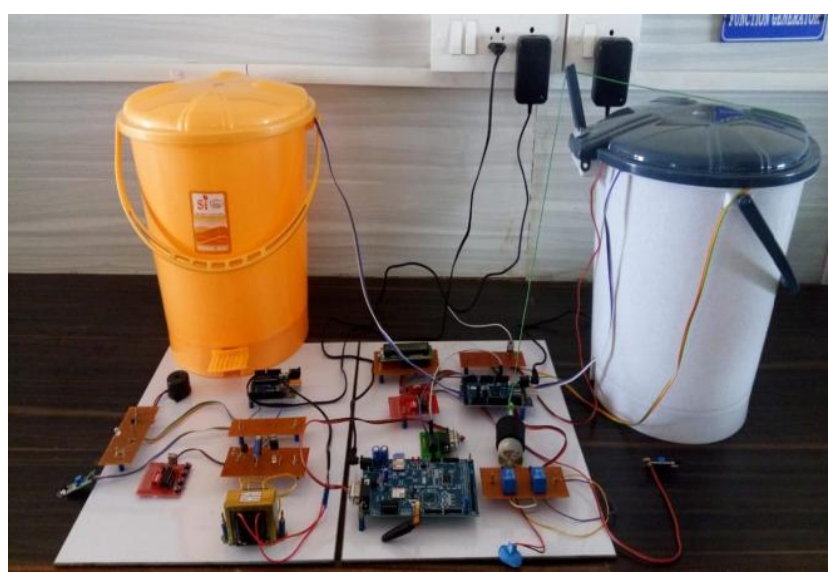

Fig: 6 Complete Hardware Unit

Various sensors were tested by using program and the output obtained was monitored in Arduino software. The figure below shows the output of ultrasonic sensor which was tested.

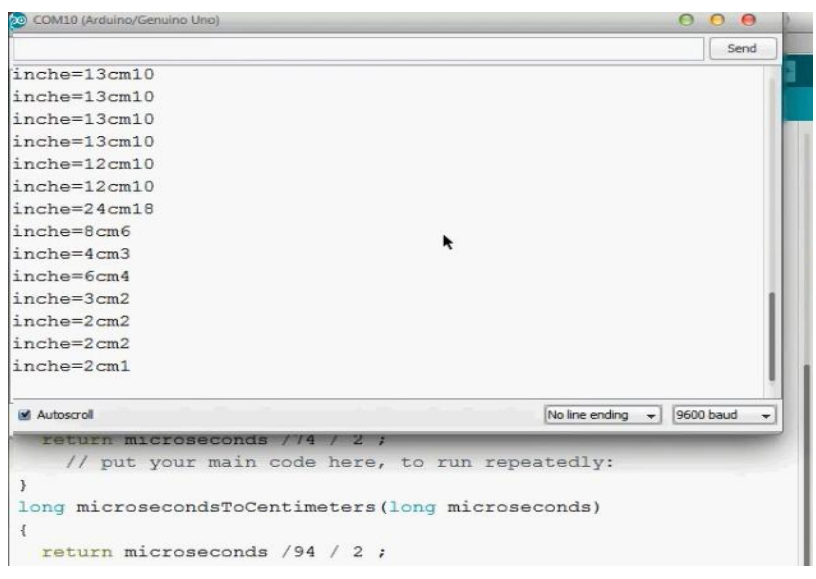

Fig:7 Hardware testing of ultrasonic sensor

The figure above shows the testing of ultrasonic sensor at various distances.For various distances the output obtained from the sensor is monitored and tabulated. The table below shows the distance in $\mathrm{cm}$ and the output voltage in volts.

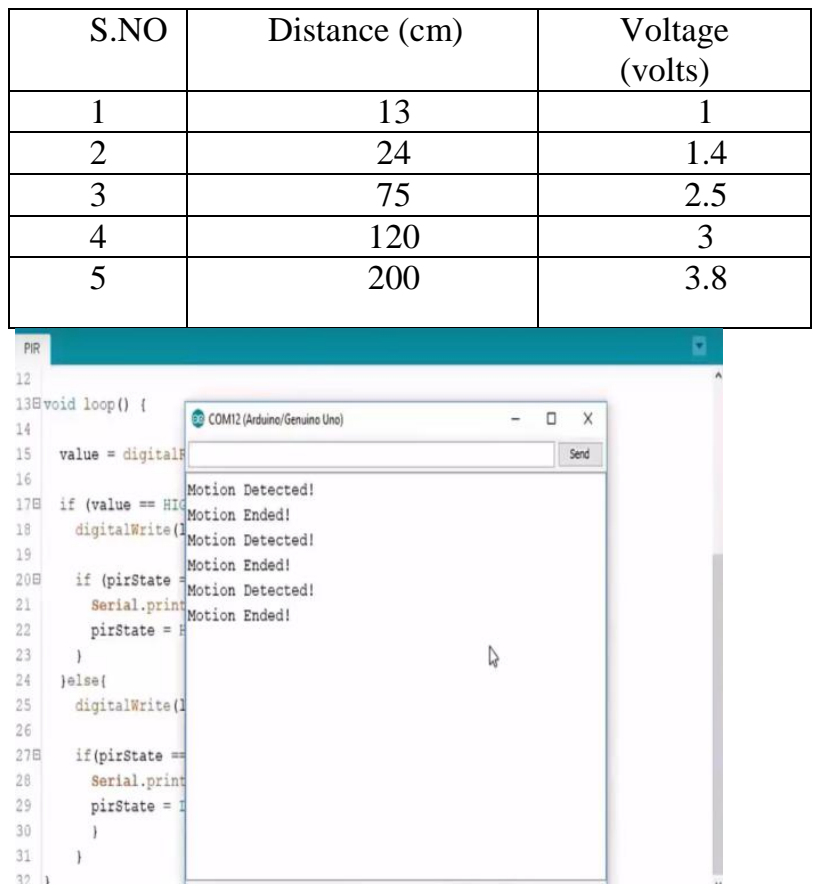

Fig:8 Hardware testing of IR sensor

The figure above shows the hardware testing of IR sensor

\begin{tabular}{|c|c|c|c|}
\hline 1 & Ravi_TN01AB5555 & 03/10/2019 & 11:41:09 \\
\hline 2 & Bin_1_Full & 03/10/2019 & 11:41:38 \\
\hline 3 & Bin_1_Full & 03/10/2019 & 11:42:10 \\
\hline 4 & Bin_1_Full & 03/10/2019 & 11:42:43 \\
\hline 5 & Bin_1_Full & 03/10/2019 & 11:43:14 \\
\hline 6 & $L 1=264 \_L 2=024 \_M=23 \_G=144 \_$ & 03/10/2019 & $11: 43: 46$ \\
\hline 7 & $L 1=263 \_L 2=024 \_M=17 \_G=143 \_$ & 03/10/2019 & 11:44:18 \\
\hline 8 & Bin_1_Full & 03/10/2019 & $11: 44: 49$ \\
\hline 9 & $L 1=044 \_L 2=024 \_M=21 \_G=139$ & 03/10/2019 & $11: 45: 20$ \\
\hline 10 & $\mathrm{~L} 1=060 \_\mathrm{L} 2=024 \_\mathrm{M}=23 \_\mathrm{G}=140 \_$ & 03/10/2019 & $11: 45: 52$ \\
\hline 11 & $\mathrm{~L} 1=053 \_\mathrm{L} 2=024 \_\mathrm{M}=16 \_\mathrm{G}=137 \_$ & 03/10/2019 & $11: 46: 24$ \\
\hline 12 & $L 1=027 \_L 2=024 \_M=21 \_G=142$ & 03/10/2019 & $11: 46: 55$ \\
\hline 13 & $\mathrm{~L} 1=039 \_\mathrm{L} 2=024 \_\mathrm{M}=22 \_\mathrm{G}=134 \_$ & 03/10/2019 & $11: 47: 27$ \\
\hline 14 & $\mathrm{~L} 1=022 \_2=024 \_\mathrm{M}=21 \_\mathrm{G}=132$ & 03/10/2019 & $11: 47: 58$ \\
\hline 15 & Bin_1_Full & 03/10/2019 & $11: 48: 30$ \\
\hline 16 & $L 1=022 \_2=024-M=: 18 \_G=128 \_$ & 03/10/2019 & 11:49:01 \\
\hline 17 & $\mathrm{~L} 1=265 \_\mathrm{L} 2=228 \_\mathrm{M}=23 \_\mathrm{G}=125 \_$ & 03/10/2019 & 11:49:33 \\
\hline 18 & $L 1=263 \_L 2=227 \_M=: 19 \_G=131$ - & 03/10/2019 & 11:50:04 \\
\hline 19 & $L 1=279 \_L 2=227 \_M=19 \_G=133 \_$ & 03/10/2019 & 11:50:36 \\
\hline 20 & $\mathrm{~L} 1=262 \_\mathrm{L}=226 \_\mathrm{M}=23 \_\mathrm{G}=135$ & $03 / 10 / 2019$ & 11:51:08 \\
\hline
\end{tabular}

Fig: 9 Screenshot of web server

In the web server the details about the bin unit and vehicle unit is uploaded. The information about the vehicle number and date and time of collection is uploaded. Details about the bin unit such as level, gas content and humidity content is continuously monitored and uploaded.

\section{V.CONCLUSION}

The real time smart dumpster system can we intend to propose a technological process for waste management system. This paper shows the implementation of Smart Intelligent Garbage Alert System using Ultrasonic sensor, microcontroller and GSM module. This Smart Dumpster can contribute a lot towards creating a clean and hygienic environment in building a smart city. The cleaning of dustbins is assured as soon as

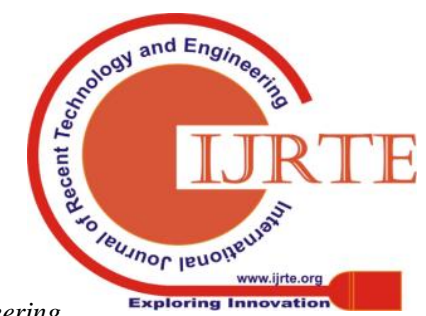


the garbage bin gets filled. If the dustbin is not cleaned at the right time then a report will be sent to the higher authorities. It also helps in saving the fuel by reducing the number of trips of the garbage collecting vehicle as it would only come to collect the garbage when the bin reaches its maximum level. By implementing this proposed system the cost reduction, resource optimization, effective usage of smart Dumpster can be done.

\section{REFERENCE}

[1]L Saranya, P Rajeshwari, M Priyadharshini, S S Praveen, G Pradeep "Garbage Management System For Smart City Using IOT" International journal of Pure and Applied Mathematics(IJPAM)

[2]Dr.V.Jamuna, S.Sivajothi Kavitha, M.Karthik Sharan, C.Gopinath, M.Aswin, (2017), "An integrated sensor network to enhance the performance of Gully pot monitoring system", international journal of advanced research in management, architecture, technology and engineering. Volume 3, special issue, PgNo:48 to 52, March 2017, ISSN: 2454-9762

[3]S.Sivajothi Kavitha, C.Lily sardonyx, J.L.N.Karunya, M.Harish (2017), "Harnessing kinetic power and sound power using PZT in a condensed zone". International journal of advanced research in Management, Architecture, Technology and Engineering (IJARMATE) Volume 3, Special issue 13 PgNo: 74 to 78 , ISSN: $2454-9762$

[4]V.Jamuna, S.Sivajothi Kavitha, S,Samuel berkins, P.Nagarajan, S.Narendran(2018), "A monotonous cyborg for an assessment of solid waste management in multistoried buildings",. International journal of scientific research and innovation, volume 3, PgNo:7 to 12, ISSN: 2455-7579.

[5]Sharaaf N. A.,Hijaz A.J.M,Kiroshan T,Suresh R,S.G.S Fernando "Easy Clean - A Smart Solution for Garbage Finding and collecting"InternationalJournal of Computer Applications (0975 - 8887) Volume 169 - No.3, July 2017 Colombo Sri Lanka.

[6] Mohd.Talha, Raaziyah Shamim, M.Salim Beg "A Cloud integrated wireless garbage management system for Smart Cities" International Conference on Multimedia, Signal Processing and Communication technologies (IMPACT) November 2017 Aligarh, India.

[7].Chandradeep Tiwariet, Smt. Nagarathna. K "Waste Management using Solar Smart Bin"International Conference on Energy, Communication, Data Analytics and Soft Computing (ICECDS) 2017.

[8]Bharadwaj B, M Kumudha, Gowri Chandra N, Chaithra G "Automation of smart waste management using IoT to support Swachh Bharat Abhiyan- A practical approach" 2nd International Conference on Computing and Communication Technologies (ICCCT) 2017.

[9]ShilanAbdullah Hassan,Noor Ghazi M.Jameel,Boran Sekeroglu "Smart solid waste monitoring and collection system" International journal of advanced research in computer science and software engineering Volume 6, 2016.

[10]Jobin Francis, Melbin TL, Praveen CN "Solar Power Smart Waste Bin" International journal of computer engineering in research trends Volume 2 2015.

[11]Naman Sharma, NikhilMishra, Paurvi Gupta "IoT based garbage monitoring system" International Journal of advance reaserch, ideas and innovations in technology Volume 4

[12]Najaf Ali, M. Muzammul, Ayesha Zafar "Intelligent System for Garbage collection: IoT technology with Ultrasonic sensor and Arduino Mega" IJCSNS International Journal of Computer Science and Network Security, VOL.18 No.9, September 2018

[13]Priya G, Ronit Chaudhuri, Pritthish Chattopadhyay, Sreyam Dasgupta "Smart Garbage Monitoring System" International Journal of Engineering Research \& Technology (IJERT)Vol. 6 Issue 05, May - 2017 